\title{
Pendekatan Terapi Rasional Emotif Tingkah Laku dalam Menangani Sifat Kebergantungan Remaja
}

\section{(Rational Emotive Behaviour Therapy for Emotional Dependency in Relationship among Youth)}

\author{
Abdul Rashid Abdul Aziz ${ }^{*}$ (D), Nurun Najihah Musa² \\ 1Fakulti Kepimpinan dan Pengurusan, Universiti Sains Islam Malaysia (USIM), 71800, Nilai. Negeri \\ Sembilan, Malaysia. \\ Email: rashid@usim.edu.my \\ ${ }^{2}$ Fakulti Kepimpinan dan Pengurusan, Universiti Sains Islam Malaysia (USIM), 71800, Nilai. Negeri \\ Sembilan, Malaysia. \\ Email: nurunmusa98@gmail.com
}

\section{CORRESPONDING \\ AUTHOR (*): \\ Abdul Rashid Abdul Aziz \\ (rashid@usim.edu.my) \\ KATA KUNCI: \\ Pemikiran tidak rasional \\ Kes klien \\ Sifat kebergantungan \\ REBT}

\section{KEYWORDS:}

Irrational belief

Client case

Dependency

REBT

\section{CITATION:}

Abdul Rashid Abdul Aziz \& Nurun Najihah Musa. (2022). Pendekatan Terapi Rasional Emotif Tingkah Laku dalam Menangani Sifat Kebergantungan Remaja. Malaysian Journal of Social Sciences and Humanities (MJSSH), 7(2), e001313.

https://doi.org/10.47405/mjssh.v7i2.1313

\begin{abstract}
ABSTRAK
Remaja yang sedang berkembang pastinya memerlukan bimbingan dan didikan daripada keluarga untuk meneruskan kehidupan dan mendepani cabaran dari satu peringkat ke peringkat perkembangan yang lain. Apabila remaja ini tidak mendapat bimbingan dan didikan daripada keluarga, mereka mula mencari seseorang yang lain yang dirasakan dapat membantu dan menenangkan diri mereka ketika berhadapan masalah terutamanya apabila berlakunya masalah dalam keluarga. Namun, jika hal ini berterusan, remaja akan menjadi terlalu bergantung kepada rakan tersebut sehingga menimbulkan rasa kecewa jika tindak balas yang diharapkan tidak berlaku. Situasi ini berlaku terhadap klien di dalam kajian ini. Hal ini terjadi apabila pemikiran tidak rasional mula muncul dalam diri klien tersebut. Oleh itu, pendekatan Terapi Rasional Emotif Tingkah Laku (REBT) digunakan untuk membantu klien tersebut untuk berfikir secara rasional dan tidak lagi melukakan emosi sendiri. Pendekatan ini didapati dapat membantu seseorang supaya berfikir secara rasional dan mendapat kegembiraan dalam hidup. Konklusinya, kajian ini dijalankan untuk melihat sejauh mana pendekatan REBT dapat membantu klien dalam menangani isu kebergantungan terhadap rakan sebaya. Dapatan daripada kajian ini dapat memberi manfaat kepada pihak-pihak berkaitan seperti kaunselor, pihak sekolah, ibu bapa, dan individu yang terlibat dalam isu yang hampir sama.
\end{abstract}

\section{ABSTRACT}

Adolescents need guidance and proper education from family in living life and to face obstacles from one developmental stage to another. When adolescents do not get guidance and education from the family, they start looking for someone else who they think is able to help and 
calm themselves when facing any problems in their life. However, if this continues, the adolescent will become too dependent on the friend and will face frustration if the expected response was not achieved. This situation was faced by a client in this study. This happens when irrational beliefs begin to appear in the client's thoughts. Therefore, the theory of Rational Emotive Behavior Therapy (REBT) is used to help the client to think rationally without hurting their own emotions. This theory was found to help an individual to think rationally in helping them to achieve happiness in life. In conclusion, this study was conducted to see the effectiveness of REBT theory in assisting clients to address the issue of emotional dependence towards their on peer. Findings from this study can benefit relevant parties such as counselors, school authorities, parents, and individuals which involved with similar issues.

Sumbangan/Keaslian: Kajian ini menyumbang dalam menguatkan lagi literatur sedia ada. Kajian ini juga menggunakan metodologi kajian kes yang dapat dijadikan rujukan pelajar dalam mengaplikasikan teori yang digunakan dalam menjalankan sesi kaunseling. Kajian ini menyumbang analisis logik keberhasilan sesuatu teori.

\section{Pengenalan}

Kepincangan institusi keluarga menjadi faktor kebergantungan anak beralih arah mencari sumber lain untuk menyokong kehidupan mereka. Di peringkat remaja, perhatian sepenuhnya harus diberikan untuk membantu perkembangan sihat seseorang remaja. Oleh itu, saat ini merupakan fasa penting untuk ibu bapa menjadi 'kawan rapat' yang memahami emosi, psikologi dan keperluan anaknya. Namun, perkara sebaliknya berlaku apabila ibu bapa gagal memahami anak dan menyebabkan mereka menjadikan rakan seusia orang rapat di dalam hidup mereka.

Mempunyai rakan-rakan yang positif dan pencapaian tinggi memberi kesan positif ke atas kepuasan remaja di sekolah, kemajuan pendidikan, gred buku rekod, dan skor ujian pencapaian (Nik Abdul Rashid, 2014). Namun kebergantungan yang terlalu tinggi boleh mengakibatkan kesan negatif jika diamalkan dalam jangka masa yang panjang seperti terlalu berharap kepada pertolongan, tidak dapat membuat keputusan sendiri dan akhirnya menjerumuskan seseorang kepada pemikiran tidak rasional. Hal ini telah berlaku pada klien yang dikenali dengan nama Wadi. Oleh itu, pengkaji menjadikan pendekatan REBT sebagai intervensi dalam membantu klien berhubung sifat kebergantungan terhadap rakan seusia. REBT digunakan dengan meletakkan situasi klien dalam kaedah A (Activating event), B (Belief), C (Consequence), D (Dispute), E (Effect) dan F (New Feeling).

\subsection{Latar Belakang Kajian}

Wadi (bukan nama sebenar) berumur 19 tahun dan menetap di Perak serta merupakan seorang penuntut di salah sebuah institut pendidikan tinggi. Klien sedang menjalani pengajian di peringkat Sarjana Muda Pendidikan dan berada di semester dua ketika sesi dijalankan. Klien merupakan anak sulung dalam keluarga. Klien mempunyai bapa yang bersikap panas baran. Selain itu, klien juga menyatakan ibu bapanya sering bergaduh ketika klien masih kecil kerana bapanya pernah berlaku curang. Perkara-perkara ini 
menyebabkan hubungan klien dan ibu bapanya tidak terlalu baik. Klien tidak pernah berkongsi sebarang masalah bersama keluarganya bahkan telah menjadikan rakan sebaya sebagai tempat meluah dan mendapatkan sokongan jika memerlukan. Hal ini bermula daripada zaman sekolah menengah dan apabila klien menyambung pelajaran ke institut pengajian tinggi, klien mula mencari rakan untuk dijadikan kenalan rapat. Kenalannya telah menjadi kawan yang sentiasa berkongsi masalah dan menjadi tempat bergantung dalam apa jua keadaan. Hal tersebut menyebabkan klien mewujudkan hubungan yang baik dengan kawan rapatnya, namun keadaan berubah apabila klien mengesan rakannya berubah sikap terhadapnya secara mendadak. Hal ini disedari apabila, rakannya lambat membalas mesej aplikasi WhatsApp dan tidak mengendahkannya. Berikutan hal tersebut, klien telah menyedari rakannya tidak memberi perhatian kepadanya. Hal ini menyebabkan klien berasa sedih dan kecewa kerana tiada siapa mengambil berat akan dirinya.

\subsection{Permasalahan}

Klien menyatakan bahawa beliau mempunyai masalah keluarga sejak kecil menyebabkan hubungan beliau dengan keluarga tidak terlalu baik. Klien tidak pernah menceritakan apa-apa masalah kepada keluarganya. Klien lebih banyak berkongsi masalah dan mendapatkan sokongan daripada rakan-rakan sekolahnya. Klien juga berjaya mendapat kawan rapat apabila memasuki Institut Pengajian Guru (IPG). Namun, setelah memasuki semester ketiga, klien mula nampak perubahan pada kawan rapatnya. Klien merasakan kawannya itu mula mengabaikannya, tidak memberi perhatian seperti sebelumnya dan mula lambat membalas mesej melalui aplikasi WhatsApp. Disebabkan hal itu, klien mula merasakan bahawa kawannya tidak lagi memberi perhatian kepadanya menyebabkan klien merasa tiada siapa yang mengambil berat tentang dirinya. Klien merasakan bahawa tiada siapa lagi yang sayang akan dirinya dan hilang tempat bergantung. Klien menjadi sedih dan berputus asa untuk meneruskan hidup.

Berdasarkan penceritaan tersebut, klien didapati mempunyai pemikiran tidak rasional terhadap perubahan sikap kawannya. Pemikiran tidak rasional tersebut semakin meningkat apabila pelajar IPG diminta menjalankan Pengajaran dan Pembelajaran (PdP) di rumah atas arahan kerajaan untuk melaksanakan Perintah Kawalan Pergerakan (PKP). Apabila PKP dilaksanakan, pelajar tidak lagi dapat berkumpul bersama kawan-kawan dan menerima PdP secara bersemuka. Hal ini menyebabkan klien semakin terasa kosong dan tidak gembira disebabkan oleh hubungan yang tidak baik dengan keluarga dan tiada tempat untuk beliau meluahkan segala masalah. Klien juga didapati mempunyai tahap self-love yang rendah menyebabkan klien tidak gembira menjalani kehidupannya. Kebergantungan terhadap kawannya juga terlalu tinggi sehingga klien mula berasa tiada yang sayang akan dirinya selepas kawan tersebut berubah tingkah laku. Hal ini mengganggu kefungsian harian klien apabila klien tidak lagi dapat berfikir secara rasional dan asyik memikirkan tentang perubahan sikap kawannya. Berfikir secara berlebihan ini telah menyebabkan klien merasa tidak mahu lagi meneruskan hidupnya.

Oleh itu, kajian kes kaunseling ini dijalankan adalah untuk membincangkan pendekatan REBT dalam mengatasi sifat kebergantungan kepada rakan serta menyelesaikan masalah yang dihadapi agar klien dapat meneruskan hidup dengan baik. Klien juga dibantu dari sudut mengaplikasikan aktiviti yang dapat meningkatkan rasa sayang terhadap diri sendiri dan tidak terlalu bergantung kepada orang lain. 


\section{Sorotan Literatur}

Pengaplikasian teknik REBT telah digunakan untuk mengenal pasti dan menganalisis masalah klien. Mustaffa (2020) menyatakan bahawa REBT sebelumnya dikenali sebagai Rational Emotive Therapy (RET) dan dikembangkan oleh Albert Ellis pada tahun 1950-an. Teori REBT merupakan kaedah yang membantu klien untuk merasionalkan emosi dan tingkah laku yang negatif atau tidak diingini dengan mengubah emosi dan tingkah laku yang rasional untuk mengatasi masalah yang berlaku (Nucci, 2002). Teori ini memperlihatkan bahawa emosi tidak tercetus disebabkan perkara atau masalah yang berlaku sebaliknya berpunca menerusi cara individu mentafsir, menilai dan tanggapan terhadap sesuatu perkara yang berlaku (Ellis, Gordon, Neenan \& Palmer, 1997). Justeru, REBT digunakan dengan meletakkan situasi klien dalam kaedah A (Activating event), B (Belief), C (Consequence), D (Dispute), E (Effect) dan F (New Feeling).

Menurut satu kajian kes yang dilakukan oleh Purbaning Tyas (2015) ke atas sekumpulan mahasiswa menunjukkan teori REBT yang digunakan sepanjang sesi kelompok berjalan telah menyebabkan mahasiswa yang terlibat mula menyedari kelebihan yang terdapat dalam diri mereka. Mahasiswa tersebut juga mula mempunyai rasa yakin diri yang tinggi. Mereka mampu mengawal emosi dengan baik dan secara positif serta menjadi fleksibel dalam menghadapi sebarang perubahan yang berlaku. Ini membuktikan bahawa teori REBT yang digunakan dapat membantu klien mengawal emosi dan mendapatkan semula keyakinan diri dengan mengetahui kelebihan yang ada pada diri sendiri (Md Zahir et al., 2019; Siahaan, 2020). Perkara ini berkaitan dengan isu yang dihadapi oleh klien dalam kajian ini. Oleh yang demikian, pengkaji menggunakan teori yang sama bagi melihat keberkesanan teori tersebut selain membantu klien dengan isu yang dihadapi.

Selain itu, kajian yang dilakukan oleh Hasibuan dan Wulandari (2015). terhadap mangsa buli menunjukkan peningkatan self-esteem setelah menggunakan teori REBT ketika sesi. Proses rawatan yang dijalankan sebanyak empat sesi menggunakan REBT tersebut menunjukkan kejayaan apabila mangsa-mangsa buli yang terlibat dengan rawatan itu mampu untuk menggantikan pemikiran negatif dengan pemikiran yang lebih positif. Mereka mampu melawan pemikiran negatif yang hadir sekaligus mengenal pasti pemikiran negatif yang perlu dikawal terutamanya ketika berlaku isu buli. Perkara ini membuktikan pernyataan daripada Teaster (2004), yang menyatakan pernyataan positif tentang diri dapat meningkatkan self-esteem. Begitu juga dengan hasil penelitian oleh Mann (2004) yang menunjukkan bahawa semakin individu melihat perkara-perkara positif dalam dirinya berbanding perkara negatif yang wujud, maka self-esteem dalam diri individu tersebut akan semakin meningkat.

Kajian oleh Nielsen et al. (2001), mendapati bahawa pendekatan REBT agak sesuai kepada klien Kristian, Jewish, Muslim, Hindu dan agama lain. Mereka mempamerkan kemahuan untuk mendapatkan kepercayaan yang betul, memberikan kerjasama dalam sesi terapi dan melakukan tugasan yang diberi. Ini memberikan gambaran tahap penerimaan yang baik terhadap REBT. Robb (2002), percaya bahawa seharusnya objektif untuk memahami REBT dan agama perlu dibina agar pengamal REBT dapat berfungsi dengan cemerlang terhadap penganut Yahudi, Kristian, Islam, Hindu, Buddha, Taois, Shinto dan agama-agama lain. Pendekatan REBT juga dikatakan sesuai dengan individu beragama kerana ianya mencabar pemikiran tidak rasional seseorang, bukannya mencabar agama yang dianuti. 
Menurut Nik Rosila (2013), al-Ghazali merupakan salah satu tokoh yang memperkenalkan "terapi berlawanan" (opposite therapy) yang mencabar penggunaan akal rasional. Melalui terapi ini, klien perlu melawan sifat-sifat buruk seperti marah kepada sabar, benci kepada suka, jahil kepada berilmu. Al-Quran juga menyebutkan dorongan-dorongan berfikir dan menggunakan akal fikiran untuk melihat kebesaran dan kekuasaan Allah SWT (Surah al-Mukminun, 23: 80). Ini menunjukkan bahawa terapi kognitif seperti REBT bukanlah sesuatu yang asing dalam kaunseling Islam. Islam juga meletakkan peranan akal di tempat yang tinggi dan berperanan besar. REBT boleh disesuaikan untuk klien Muslim dalam proses untuk mengubah pemikiran dan tingkah laku. Manakala nilai-nilai Islam digunakan untuk menggantikan pemikiran-pemikiran tidak rasional yang dimiliki oleh klien (Masroom et al., 2015).

\subsection{Perspektif Islam}

Islam merupakan agama yang menyeluruh dan lengkap mempunyai pandangan alam kepada manusia, alam, dan Penciptanya. Jika pandangan alam ini dihayati dan difahami dengan mendalam, ianya dapat memberi kesan yang sangat baik dan positif kepada kesihatan mental. Bahkan sebagai seorang muslim, percaya kepada Allah menjadi syarat utama dalam melakukan segala perkara dalam kehidupan. Menurut Malaysian Mental Health Association (2012), kesihatan mental melibatkan tiga persoalan utama iaitu apakah perasaan dan pandangan seseorang terhadap dirinya; apakah perasaan dan tanggapannya kepada orang lain; dan bagaimana seseorang itu mempunyai kebolehan untuk menangani keperluan-keperluan hidup. Perkara-perkara ini bersesuaian dengan kajian yang sedang dilakukan yang mana klien mempunyai isu dalam pandangannya terhadap diri sendiri, tanggapan kepada orang lain, dan kebolehannya mengatasi masalah dalam hidup.

Manusia diciptakan dalam keadaan yang paling sempurna jika dibandingkan dengan penciptaan-penciptaan yang lain seperti pokok, haiwan dan hidupan lain. Disebabkan kesempurnaan tersebut, manusia dijadikan sebagai khalifah di muka bumi bagi menguruskan dunia ini. Manusia diciptakan dengan keistimewaan tersendiri seperti akal, nafsu dan pancaindera yang melayakkan manusia menjadi khalifah berbanding makhlukmakhluk lain. Firman Allah S.W.T dalam surah at-Tin (95:5) yang bermaksud "Sesungguhnya kami telah menciptakan manusia dalam bentuk yang sebaik-baiknya (dan berkelengkapan sesuai dengan keadaannya". Berdasarkan firman ini, manusia sepatutnya bersyukur dan berbangga dengan segala keistimewaan yang dikurniakan sehingga layak bergelar sebagai khalifah. Manusia yang sedar dan berfikiran positif akan mencari potensi diri dan cuba mengilapnya agar dapat memberi manfaat kepada seluruh kehidupan di dunia. Klien tidak seharusnya merendahkan diri dan berasa tidak berguna apabila tidak mencapai sesuatu perkara yang diingini kerana pasti ada kelebihan lain yang dimilikinya.

Islam juga mengajar umatnya agar menyayangi dan mencintai sesama makhluk. Keperluan untuk berkasih sayang, saling mencintai merupakan satu keperluan asas berdasarkan teori Hierarki Maslow. Manusia dijadikan mempunyai emosi dan kebolehan untuk merasakan cinta dan sayang. Kasih suami kepada isteri, isteri kepada suami, ibubapa kepada anak-anak, sesama rakan, saudara mara, adik beradik, jiran tetangga dan sesama ahli masyarakat adalah sesuatu yang bersifat semula jadi yang bertepatan dengan fitrah manusia yang menjadi sebahagian tanda-tanda kebesaran Allah s.w.t dengan sifat ar-Rahman dan ar-RahimNya. Firman Allah s.w.t. dalam surah ar-Rum (30:21) yang bermaksud, 
"Dan di antara tanda-tanda yang membuktikan kekuasaannya dan rahmatNya bahawa ia menciptakan untuk kamu (Wahai kaum lelaki), isteri-isteri dari jenis kamu sendiri, supaya kamu bersenang hati dan hidup mesra dengannya, dan dijadikannya di antara kamu (suami isteri) perasaan kasih sayang dan belas kasihan. Sesungguhnya yang demikian itu mengandungi keterangan-keterangan (yang menimbulkan kesedaran) bagi orang-orang yang berfikir".

Berdasarkan firman ini, dapat dilihat bahawa Allah amat menggalakkan umatnya berkasih sayang antara satu sama lain. Bukanlah menjadi sesuatu yang salah apabila kita tidak menerima kasih sayang seperti yang diharapkan. Bahkan dengan terus menyayangi insan lain dengan ikhlas pasti akan mendapat ganjaran yang setimpal yang dijanjikan oleh-Nya. Dalam kajian ini, meskipun klien mempunyai isu dengan keluarganya sejak kecil, itu tidak menghalang klien dari terus menyayangi mereka terutamanya ibu dan ayah yang memegang pangkat yang tinggi di dalam Islam.

Islam merupakan sebuah agama yang mementingkan hubungan sesama manusia. Bahkan Nabi Muhammad s.a.w. diutus untuk menunjukkan akhlak mulia. Islam mengajar manusia untuk menghormati, berlaku adil dan saksama sesama manusia tanpa mengira sama ada manusia tersebut merupakan ahli keluarga, jiran tetangga, rakan-rakan, dan manusia lain. Namun, tidak semua manusia mempunyai tahap keimanan, kefahaman dan pengamalan yang baik. Latar belakang, suasana persekitaran dan cara didikan memainkan peranan bagaimana seseorang itu bertindak dalam kehidupannya. Individu yang tidak rasional selalu mengharapkan orang di sekelilingnya melayaninya dengan layanan yang baik (Joffe-Ellis, 2006). Semua kehendak, harapan dan impiannya ingin dipenuhi oleh orang lain. Mereka juga ingin semua orang dapat menerima dirinya. Masalah akan timbul apabila keinginan dan harapannya tidak dipenuhi. Perkara inilah yang dialami oleh klien sebelum menjalani sesi kaunseling. Klien merasakan dirinya perlu disayangi oleh kawan rapatnya. Apabila perkara tersebut tidak tercapai, klien mula merasa sedih, kecewa dan rasa tidak mahu meneruskan kehidupan. Namun apabila klien memahami konsep hubungan sesama manusia, klien lebih bersyukur, redha dan memahami setiap perkara yang berlaku.

\section{Metod Kajian}

\subsection{Kaedah mendapatkan data}

Kajian dilakukan secara sesi kaunseling individu. Sesi kaunseling berjalan sebanyak empat sesi. Pengkaji menggunakan teknik asas kaunseling dalam mendapatkan maklumat daripada klien. Soalan terbuka dan tertutup juga diaplikasikan oleh pengkaji bagi mendapatkan maklumat lanjut tentang diri klien dan peristiwa yang telah dilalui. Klien menghadirkan diri secara sukarela bagi menjalani sesi kaunseling. Pada awal sesi, klien menyatakan kerisauan dan rasa malu untuk meminta bantuan kaunselor berkaitan isu yang dialami. Klien seolah-olah tidak menerima perasaan yang hadir dalam dirinya menyebabkan klien was-was untuk menjalani sesi kaunseling. Namun, selepas pengkaji membina hubungan dengan klien, klien mula yakin dan selesa berkongsi isunya dengan pengkaji. Perkara ini memudahkan lagi pengkaji untuk mendapatkan maklumat sekaligus menjalankan kajian bagi melihat keberkesanan teori REBT dalam membantu masalah klien. 


\subsection{Ujian Psikologi yang Digunakan}

Dalam kajian ini, pengkaji menggunakan ujian Depression Anxiety Stress Scale (DASS) (Musa et al., 2007) untuk menilai tahap emosi yang dialami klien. Ujian ini dibuat untuk memajukan proses dalam menentukan, memahami dan mengukur keadaan emosi yang biasanya disebut sebagai kemurungan, kerisauan dan tekanan. DASS merupakan pengumpulan tiga skala laporan diri yang digunakan untuk menilai emosi negatif yang hadir seperti kemurungan, kerisauan dan tekanan. Ujian ini memiliki 21 item yang perlu dijawab oleh klien. Pengkaji menggunakan ujian ini untuk mengenal pasti tahap emosi klien serta membantu pengkaji meneroka secara lebih mendalam. Ujian ini juga dilakukan bagi melihat sejauh mana kebergantungan rakan sebaya mempengaruhi emosi seseorang.

Pada sesi pertama dijalankan, klien kelihatan seolah-olah tidak dapat mengawal dirinya. Klien meluahkan rasa geram dan kecewanya melalui nada percakapan dan bahasa tubuh badan. Kaunselor meminta klien untuk menjalani ujian DASS. Daripada keputusan ujian DASS tersebut, klien didapati mengalami tahap kemurungan dan kerisauan yang teruk dengan jumlah skor 14 dan 10. Manakala tahap tekanan yang dihadapi berada di tahap ringan dengan jumlah skor 8. Ujian tersebut digunakan oleh pengkaji bagi meneroka lebih mendalam perasaan dan emosi yang sedang dialami oleh klien. Ujian ini juga digunakan bagi melihat perkembangan diri klien dari segi emosi yang dilalui sebelum dan selepas sesi dijalankan. Klien didapati menghadapi kemurungan dan kerisauan yang tinggi apabila klien mula menyatakan tentang tidak guna lagi untuk hidup, tiada yang menyayangi dirinya, dan ayat-ayat lain yang membuktikan ketidakstabilan emosi klien ketika itu. Namun, setelah beberapa sesi dijalankan, klien diberi semula ujian DASS dan tahap ujian DASS klien menunjukkan penurunan. Tahap kemurungan dan kerisauan klien menunjukkan perubahan kepada tahap sederhana dengan skor sembilan dan lapan berbanding tahap teruk pada sesi pertama dijalankan.

\subsection{Konseptualisasi kes}

Merujuk kepada Rajah 1, klien didapati menghadapi masalah keluarga apabila berhadapan dengan bapa yang mempunyai sikap panas baran. Klien juga berhadapan dengan pergaduhan keluarga ketika klien masih kecil.

Rajah 1: Permasalahan yang dikenal pasti oleh kaunselor

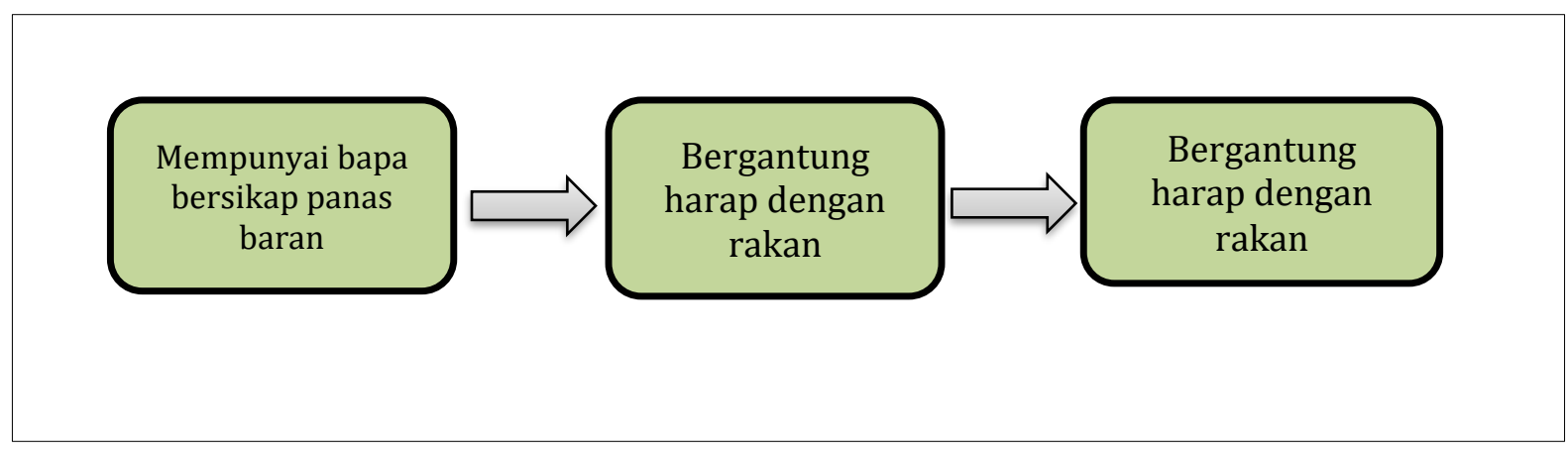

Isu keluarga yang wujud menyebabkan klien bergantung emosi dengan rakan baik yang dikenali di tempat pengajiannya. Klien sentiasa berkongsi masalah dan mewujudkan hubungan selesa dan rapat untuk memenuhi ruang kosong yang ada dalam dirinya. Kebergantungan emosi terhadap rakannya menyebabkan klien mengesan rakannya mula tidak mengendahkan dirinya. Hal ini menyebabkan klien merasa sedih, kecewa, berfikiran 
tiada siapa mempedulikannya dan berputus asa untuk meneruskan kehidupan. Kaunselor mendapati bahawa klien mengalami pemikiran tidak rasional (irrational belief system) apabila beranggapan negatif terhadap rakan baiknya. Hal ini berlaku kerana klien berasa keseorangan apabila ibu bapa tidak memberi perhatian terhadapnya pada saat klien memerlukan. Pelbagai masalah timbul sewaktu dalam pengajian membuatkan klien berasa selesa apabila dirinya dihargai dan diambil berat oleh rakannya. Walau bagaimanapun, situasi tersebut telah menimbulkan masalah kepada klien apabila klien gagal mengawal dirinya dari menerima sebarang perubahan yang berlaku terhadap rakannya.

\section{Hasil Kajian}

\subsection{Intervensi}

Hasil dari sesi kaunseling yang dijalankan pada pertama kalinya, kaunselor melakukan penerokaan terhadap isu yang dihadapi oleh klien. Klien menceritakan masalah yang dihadapi dan kaunselor menggunakan beberapa teknik seperti kemahiran menyoal, mendengar, parafrasa dan refleksi untuk menggalakkan klien menyatakan isu berkaitan sikap rakannya lambat membalas mesej di WhatsApp. Justeru pada pertemuan kali pertama ini kaunselor telah berjaya mengenal pasti beberapa masalah klien yang mendapati sikap kawannya berubah.

Manakala, berdasarkan sesi kaunseling yang dijalankan pada kali kedua, klien menyatakan bahawa dirinya berasa sedih, murung serta berputus asa untuk meneruskan kehidupan. Hal ini berikutan daripada klien merasa sedih dengan perubahan sikap kawannya serta hubungan yang jauh dengan keluarganya. Oleh itu, kaunselor melakukan penerokaan dengan lebih mendalam tentang isu yang dinyatakan klien serta membuat pertikaian terhadap pemikiran negatif klien dengan memberi persoalan tentang bukti yang menunjukkan rakannya tidak mengambil berat akan dirinya. Sementelahan itu, kaunselor memberi tugasan untuk klien membuat senarai perkara yang boleh mencetuskan rasa gembira terhadap dirinya sebelum sesi tamat.

Kemudian pada sesi perjumpaan ketiga, kaunselor membuat perbincangan dengan klien berdasarkan tugasan yang diberikan dan mendapati keadaan klien bertambah baik berbanding sebelum ini. Tugasan ini memberi rasa gembira kepada klien kerana perkaraperkara yang dilakukan adalah perkara yang diminati klien seperti melukis, bersenam secara ringan, serta membaca al-Quran. Perkara-perkara ini mendatangkan ketenteraman dan kegembiraan bahkan klien sebelum ini tidak pernah sedar dan ambil kisah tentang perkara yang menyeronokkan baginya. Kaunselor juga turut mengaplikasikan teknik REBT dengan menyarankan klien membuat tugasan untuk mengawal emosi dan menstrukturkan pemikiran dengan baik hasil dari permasalahan yang timbul. Tugasan ini dilakukan dengan meminta klien mencatat perasaan dan pemikiran negatif yang dialami seterusnya melihat permasalahan yang menyebabkan perkara negatif itu berlaku.

Apabila klien dapat mengenal pasti permasalahan yang wujud, lebih mudah untuk klien mengawal pemikiran tidak rasionalnya. Tugasan ini juga membantu pengkaji untuk melihat peningkatan yang berlaku dalam diri klien. Kaunselor memberi tugasan untuk klien membuat jadual harian untuk mengelakkan klien dari berasa keseorangan dan memenuhi masa dengan aktiviti yang bermanfaat serta menjalinkan hubungan baik dengan ahli keluarganya. Dengan menyibukkan diri mengikut jadual yang dirancang, 
klien tidak mempunyai banyak masa terluang yang membolehkan klien berfikir secara tidak rasional bahkan klien lebih menumpukan perhatian terhadap perkara yang berada di depan matanya.. Seterusnya, pada sesi akhir kaunselor melakukan semakan terhadap tugasan yang diberikan dan tindak balas yang diberi memberangsangkan apabila klien celik akal untuk menyelesaikan masalahnya dan didapati lebih tenang serta gembira menjalani kehidupannya tanpa bergantung harap dan terlalu memikirkan rakannya, juga lebih mengambil berat terhadap keluarga.

\subsection{Rawatan, Kemajuan Serta Hasil Rawatan}

Merujuk kepada Jadual 1, dapat dilihat bahawa teori REBT yang digunakan dalam membantu klien boleh dikatakan berkesan. Teknik ABCDEF dapat mengubah pemikiran tidak rasional klien kepada pemikiran yang lebih rasional. Teknik pertikaian (dispute) yang digunakan pengkaji seperti meminta bukti dan mengenal pasti sepenting mana orang lain dalam hidupnya menunjukkan kesan positif apabila klien mula mendapat celik akal selepas sesi kaunseling dijalankan. Pengkaji juga memberi beberapa tugasan untuk membantu klien bagi mengeluarkannya daripada kesedihan yang dialami. Pengkaji meminta klien menyenaraikan perkara yang dapat memberi kegembiraan kepada klien dan meminta klien melakukannya sesuai dengan keadaan semasa iaitu musim PKP ini. Klien juga disarankan untuk membuat tugasan untuk mengawal emosi dan menstrukturkan pemikiran dengan baik hasil dari permasalahan yang timbul. Klien dibimbing untuk mengenali emosi yang wujud dan menerima apa jua emosi yang hadir memandangkan pada awal sesi klien menyatakan keraguan tentang perasaannya sendiri. Apabila emosi dalam diri sudah dikenal pasti, lebih mudah untuk klien mengawal dan menstrukturkannya dengan baik.

Jadual 1: Hasil permasalahan dan kesan yang dihadapi oleh klien menerusi teknik dalam teori REBT

\begin{tabular}{|c|c|c|c|c|c|}
\hline $\begin{array}{c}\text { Krisis (Activating } \\
\text { event) }\end{array}$ & $\begin{array}{l}\text { Pemikiran } \\
\text { (Beliefs) }\end{array}$ & $\begin{array}{c}\text { Kesan kepada } \\
\text { pemikiran } \\
\text { (Consequence) }\end{array}$ & $\begin{array}{c}\text { Pertikaian } \\
\text { pemikiran } \\
\text { negatif } \\
\text { (Dispute) }\end{array}$ & $\begin{array}{l}\text { Kesan } \\
\text { (Effect) }\end{array}$ & $\begin{array}{c}\text { Emosi dan } \\
\text { pemikiran yang } \\
\text { baru (New } \\
\text { feeling) }\end{array}$ \\
\hline
\end{tabular}

\begin{tabular}{|c|c|c|c|c|c|}
\hline $\begin{array}{l}\text { Kawan berubah } \\
\text { sikap dengan } \\
\text { menjauhkan diri } \\
\text { (lambat } \\
\text { membalas } \\
\text { whatsapp, jarang } \\
\text { bertanya tentang } \\
\text { keadaannya, } \\
\text { tidak mahu } \\
\text { bercerita tentang } \\
\text { perkara yang } \\
\text { dilalui, lebih } \\
\text { mementingkan } \\
\text { permainan atas } \\
\text { talian daripada } \\
\text { mengangkat } \\
\text { panggilan dari } \\
\text { klien) }\end{array}$ & $\begin{array}{l}\text { Klien } \\
\text { berfikiran } \\
\text { bahawa dia } \\
\text { memerluka } \\
\text { n seseorang } \\
\text { yang } \\
\text { mengambil } \\
\text { berat dan } \\
\text { bersedia } \\
\text { mendengar } \\
\text { dirinya } \\
\text { Klien sering } \\
\text { menyebut } \\
\text { 'kawan ja } \\
\text { tempat } \\
\text { yang saya } \\
\text { boleh cerita } \\
\text { masalah', }\end{array}$ & $\begin{array}{l}\text { Klien berasa } \\
\text { sedih, kecewa, } \\
\text { dan tidak } \\
\text { mahu } \\
\text { meneruskan } \\
\text { hidup } \\
\text { Pengkaji } \\
\text { mendapati diri } \\
\text { klien berada } \\
\text { dalam keadaan } \\
\text { tidak terurus } \\
\text { dan klien juga } \\
\text { menyatakan } \\
\text { beliau sering } \\
\text { berkurung di } \\
\text { dalam bilik } \\
\text { dan menangis. }\end{array}$ & $\begin{array}{l}\text { Bukti yang } \\
\text { menunjukka } \\
\text { n rakannya } \\
\text { tidak } \\
\text { mengambil } \\
\text { berat akan } \\
\text { dirinya } \\
\text { Kaunselor } \\
\text { menggunaka } \\
\text { n ayat 'apa } \\
\text { bukti yang } \\
\text { menunjukka } \\
\text { n kawan } \\
\text { awak dah tak } \\
\text { peduli } \\
\text { kepada } \\
\text { awak?', } \\
\text { 'sejauh mana }\end{array}$ & $\begin{array}{l}\text {-Klien mula } \\
\text { berfikiran } \\
\text { tentang } \\
\text { dirinya } \\
\text { dengan } \\
\text { menyebut, } \\
\text { 'lepas ni saya } \\
\text { kena fokus } \\
\text { diri saya } \\
\text { dululah } \\
\text { sebelum fikir } \\
\text { pasal orang } \\
\text { lain' }\end{array}$ & $\begin{array}{l}\text { Klien berasa } \\
\text { tenang, rasional } \\
\text { dan gembira } \\
\text { untuk } \\
\text { meneruskan } \\
\text { kehidupan } \\
\text { selepas ini. Klien } \\
\text { lebih fokus } \\
\text { terhadap } \\
\text { hubungan } \\
\text { bersama keluarg } \\
\text { a } \\
\text { Antara ayat yang } \\
\text { disebut klien yang } \\
\text { menunjukkan } \\
\text { perubahan } \\
\text { dirinya adalah, } \\
\text { 'saya akan tolong }\end{array}$ \\
\hline
\end{tabular}




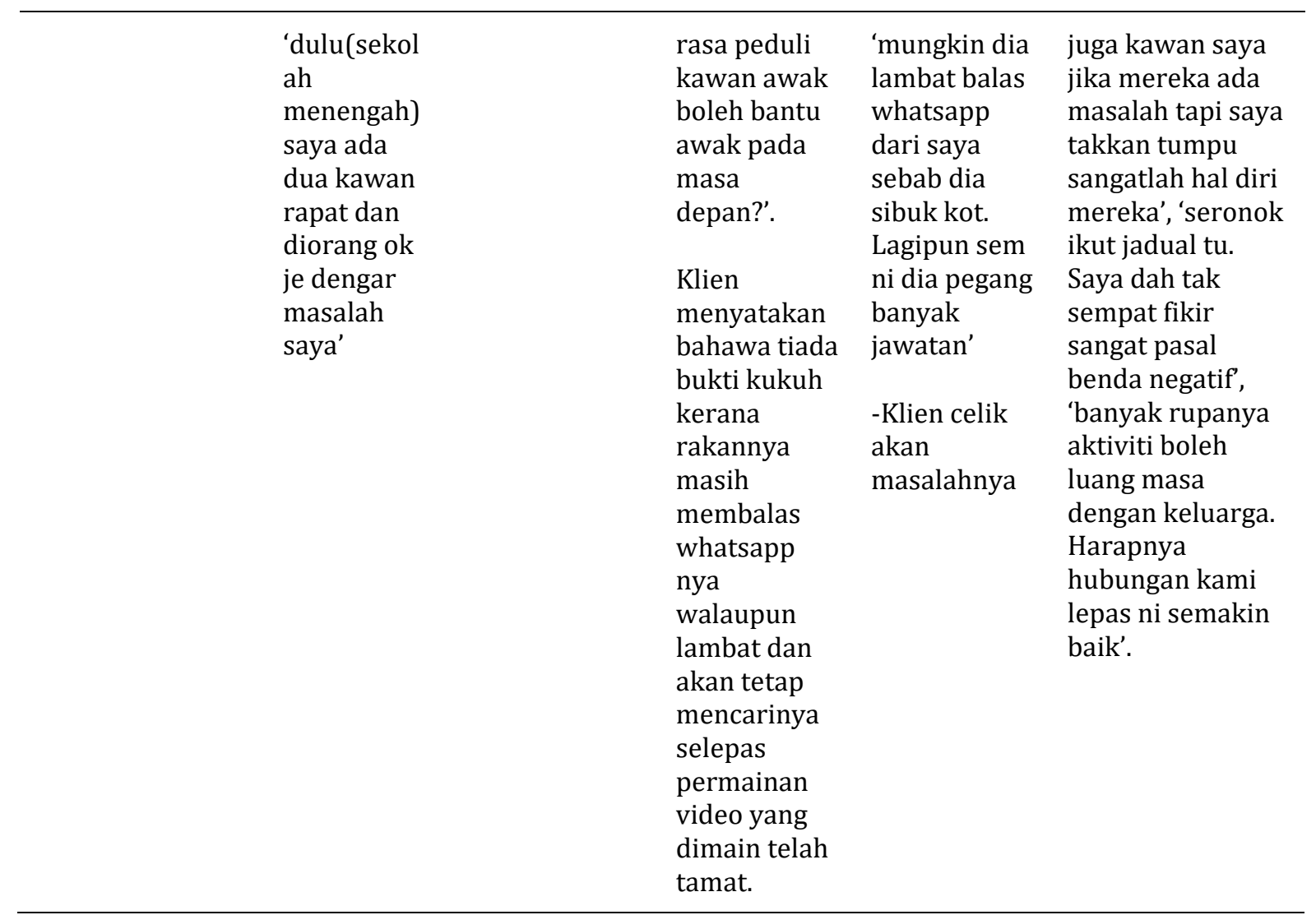

Bagi membantu isunya dengan keluarga, pengkaji menggalakkan klien untuk membuat jadual harian yang dipenuhi dengan aktiviti yang boleh dilakukan bersama keluarga. Perkara ini bertujuan untuk mengeratkan lagi hubungan klien dengan keluarganya. Aktiviti yang bersesuaian dan menyeronokkan dapat memberi kesan positif kepada emosi klien. Hasil daripada teknik dan tugasan yang diberikan, klien menunjukkan peningkatan yang positif apabila klien tidak lagi terlalu bergantung kepada rakannya dan sudah mampu untuk berdikari apabila menghadapi sesuatu masalah. Klien juga kelihatan dapat mengawal diri dan emosinya dengan aktiviti-aktiviti yang telah disenaraikan. Perkara ini membantu klien mencapai kegembiraan dalam hidup dan lebih memahami makna kehidupan. Klien juga kelihatan lebih ceria selepas beberapa sesi dijalankan. Klien juga menyatakan hubungannya dengan keluarga semakin baik setelah klien melakukan beberapa aktiviti bersama keluarganya. Klien juga lebih jelas tentang kepentingan menjaga hubungan bersama keluarga.

\subsection{Faktor Halangan}

Sepanjang sesi kaunseling dijalankan, pengkaji dan klien menghadapi beberapa isu. Pada sesi permulaan, klien dan pengkaji menghadapi isu pertembungan masa yang mana klien masih perlu menghadiri kelas dan jadualnya agak padat. Ini menimbulkan isu untuk mencari masa yang sesuai untuk melaksanakan sesi. Beberapa sesi yang telah dijadualkan terpaksa ditunda atas dasar klien tiba-tiba menerima tugasan daripada pensyarah dan perlu disiapkan segera. Isu juga timbul apabila pengkaji meminta klien menjalankan aktiviti yang telah disenaraikan. Beberapa aktiviti yang disenaraikan tidak dapat dilaksanakan disebabkan oleh perintah PKP walaupun aktiviti tersebut sangat disukai. Aktiviti yang tidak dapat dilaksanakan kebanyakannya adalah aktiviti yang melibatkan aktiviti fizikal di luar rumah. Namun pengkaji membantu klien mengenal pasti aktiviti yang bersesuaian dilakukan sepanjang perintah PKP. Walaupun tidak banyak aktiviti 
yang dapat dilakukan, pengkaji membimbing klien untuk memberi tumpuan dan menghayati aktiviti-aktiviti tersebut.

\subsection{Susulan}

Setelah sesi ditamatkan pada sesi keempat, kaunselor membuat follow-up bagi melihat kestabilan emosi yang dialami klien hasil daripada sesi-sesi yang telah dijalankan. Klien didapati dapat mengekalkan emosi yang stabil dan pemikiran yang rasional. Klien juga masih melakukan aktiviti yang menggembirakan dirinya dan mula membiasakan diri untuk membuat jadual supaya klien lebih cakna tentang apa yang perlu dilakukannya setiap hari sekaligus dapat mengurangkan masa untuk beliau terlalu melayan perasaan negatif yang tidak perlu. Dengan melihat perkembangan diri klien serta akuan daripada klien sendiri, kaunselor menyatakan bahawa sesi dijalankan setakat ini sahaja dan klien bersetuju untuk menghentikan sesi.

\section{Kesimpulan}

Tuntasnya, teori REBT yang diguna pakai terhadap permasalahan klien didapati membantu klien keluar dari masalah yang membelenggu dirinya. Hasilnya klien lebih mementingkan hubungan sesama ahli keluarga dari rakannya. Klien terasa dirinya dihargai dan tidak keseorangan apabila celik dari pemikiran negatif yang menyebabkan dirinya berasa tidak dihargai. Teknik REBT yang membantu klien merasionalkan pemikiran, emosi dan tingkah laku dapat membantu individu dari terus beranggapan negatif dan berasa murung. Hal ini kerana, masih banyak peluang dan ruang dapat digunakan untuk mencipta kehidupan yang berkualiti dan bahagia. Penerapan isu agama juga dapat membantu seseorang untuk mempunyai kesihatan mental yang lebih baik dan dapat mengawal emosi dengan cara yang sepatutnya.

\section{Penghargaan (Acknowledgement)}

Jutaan terima kasih diucapkan kepada responden yang terlibat dalam menjayakan kajian ini.

\section{Kewangan (Funding)}

Kajian dan penerbitan ini tidak menerima sebarang tajaan atau bantuan kewangan. Kajian dan penerbitan yang dilakukan adalah atas tanggungan sendiri.

\section{Konflik Kepentingan (Conflict of Interests)}

Penulis tidak mempunyai sebarang konflik kepentingan sepanjang menjalankan kajian.

\section{Rujukan}

Ellis, A., Gordon, J., Neenan, M., \& Palmer, S. (1997). Stresscounseling: a rational emotive behavior approach. New York: Springer Publishing Company.

Hasibuan, R. L. \& Wulandari, L. H. (2015). Efektivitas Rational Emotive Behavior Therapy (REBT) untuk Meningkatkan Self Esteem pada Siswa SMP Korban Bullying. Jurnal Psikologi, 11 (2). 
Joffe-Ellis, D. (2006). Albert Ellis \& Rational Emotive Behavior Therapy (REBT). Retrieved from http://www.rebtnetwork.org/

Malaysian Mental Health Association (2012). Mental health handbook. Selangor: Pfizer Sdn Bhd.

Mann, M. M., Hosman, C. M. H., Schaalma, H. P., \& de Vries, N. K. (2004). Self-esteem in a broad-spectrum approach for mental health promotion. Health Education Research, 19(4), 357-372.

Masroom, M. N., Muhamad, S. N. \& Abd Rahman, S. A. (2015). Kesihatan Mental, REBT dan muslim. Sains Humanika, 6(1), 49-57.

Md Zahir, M. Z., Saper, M. N., \& Bistamam, M. N. (2019). Kesahan dan Kebolehpercayaan Modul Kelompok Bimbingan Integrasi REBT-Tazkiyah An-Nafs. Journal of Research, Policy \& Practice of Teachers and Teacher Education, 9(1), 58-69. https://doi.org/10.37134/jrpptte.vol9.no1.6.2019

Musa, R., Ariff MF, \& Zaini Z. (2007). Translation, validation and psychometric properties of Bahasa Malaysia version of the Depression Anxiety and Stress Scales (DASS). ASEAN Journal of Psychiatry, 8(2), 82-89.

Mustaffa, N. (2020). Mengatasi Kebimbangan Semasa Pandemik Covid-19 Dengan Pendekatan Teori Rational Emotive Behaviour Therapy (REBT). Malaysian Journal of Social Sciences and Humanities (MJSSH), 5(11), pp. 10 - 16. doi: https://doi.org/10.47405/mjssh.v5i11.553

Nielsen, S. L., Johnson, W. B., \& Ellis, A. (2001). Counseling And Psychotherapy With Religious Persons: A Rational Emotive Behavior Therapy Approach. New Jersey: L. Erlbaum Associates.

Nik Abdul Rashid, N. R. (2014). Panduan hubungan dengan rakan sebaya. Myhealth. Dicapai dari http://www.myhealth.gov.my/panduan-hubungan-dengan-rakansebaya/

Nik Rosila Nik Yacob. (2013). Cognitive Therapy Approach from Islamic Psycho-spiritual Conception. Procedia - Social and Behavioral Sciences, 97, 182-187. doi:10.1016/j.sbspro.2013.10.220

Nucci, C. (2002). The rational teacher: rational emotive behavior therapy in teacher education. Journal of Rational-Emotive \& Cognitive Behavior Therapy, 20(1), 15-32.

Purbaning Tyas, P. H. (2015). Pendekatan naratif dalam konseling rational emotive behavior therapy (rebt) untuk mengelola emosi. Jurnal Fokus Konseling, 1 (2), 107 117. DOI: https://doi.org/10.52657/jfk.v1i2.97

Quran 23:80, versi Terjemahan al-Quran Bahasa Melayu.

Quran 30:21, versi Terjemahan al-Quran Bahasa Melayu.

Quran 95:5, versi Terjemahan al-Quran Bahasa Melayu.

Robb, H. (2002). Practicing Rational Emotive Behavior Therapy and Religious Clients. Journal of Rational-Emotive and Cognitive-Behavior Therapy, 20 (3-4), 169-200. doi:10.1023/A:1021160226146

Siahaan, D. N. A. (2020). Konseling kelompok dengan pendekatan REBT untuk meningkatkan kepercayaan diri anak korban kekerasan. Jurnal Pendidikan dan Konseling, 10(1).

Teaster, F.J. (2004). Positive Self-Talk Statement as a Self Esteem Buliding Tecnique Among Female Survivors of Abuse. Electronic Theses and Dissertations. Paper 975. https://dc.etsu.edu/etd/975 